\title{
Erratum to: Plane-Parallel Advective Flow in a Horizontal Incompressible Fluid Layer with Rigid Boundaries
}

\author{
K. G. Schwarz \\ The Russian Presidential Academy of National Economy and Public Administration, \\ bul'v. Gagarina 10, Perm, 614990, Russia \\ e-mail: bmontana@yandex.ru
}

DOI: $10.1134 / \mathrm{S} 0015462819110016$

Page 438 line 4 name of the author should read: K.G. Schwarz

The original article can be found online at https://doi.org/10.1134/S0015462814040036. 